\title{
Research Design of Chinese Civil Morality Education
}

\author{
Zhang Ting \\ School of Education and Psychology Science, University of Jinan, Jinan 250022, China
}

\begin{abstract}
The civil morality is closely linked with the issue of the social life of people, The practice of civil morality is based on the social morality philosophy. The civil morality philosophy is the value and spiritual prop of civil society. By comparing the subject morality, class morality and citizen's morality, the paper presents the basic guidelines for the research design of civil morality education in the development of Chinese civil society.
\end{abstract}

Keywords — citizen, civil morality education, research Design

\section{中国公民道德教育的研究预设}

张婷

济南大学教育与心理科学学院, 济南, 山东, 中国

摘 要 公民道德建设与人们的社会生活紧密相连, 公民道德建设的实践则基于社会的道德理念, 公民道德理念同时又构筑了公 民社会的价值维度和精神支柱。本文力求从臣民道德、阶级道德与公民道德的内在关联性和差异性比较中, 得出中国公民社会发展进 程中的公民道德建设研究预设。

关键词 公民，公民道德教育，研究预设

作为古希腊文明之一的公民社会, 自诞生之日起便将 公民道德作为其最重要的辩证与反思课题之一, 致力于对 人类社会 (城邦、国家) 的公共利益和个体利益的关系探 究。进至全球一体化时代, 公民道德建设依然是世界各国 社会发展的追求和理想。公民道德建设与人们的社会生活 紧密相连, 公民道德建设的实践则基于社会的道德理念, 公民道德理念同时又构筑了公民社会的价值维度和精神支 柱。

\section{1. 公民社会的道德品性}

\section{1 公民社会的天然道德内蕴}

道德先于公民社会产生, 公民社会在一定程度上是道 德浸染的结果, 公民社会先天具有道德的品性。自然法萌 生于对宇宙和自然世界的认识, 但在公元前五世纪后半叶, 古希腊民主制得到迅速发展之前, 自然法思想的核心已不 再是自然的秩序问题, 而转向人类社会的立场, 将自然法 奉为人类社会最高的道德法则。在 “没有国家、政治时的 人类社会之所以能够在一种秩序中生存, 是因为有一种自

全国教育科学规划青年基金课题（CEA120116）
然力量, 即社会道德准则和伦理规范。” [1]公民因城邦而存 在, 城邦因公民而存在, 城邦是一个公民自治共同体。亚 里士多德作为古典公民社会理论中的代表, 他认为城邦的 目的就在于促进公共善和美德, 追求公共幸福的高尚美德 生活。他在《政治学》中将公民社会理解界定为: “自由和 平等的公民在一个合法界定的法律体系之下结成的伦理一 政治共同体。” [2]显然, 他首先对 “公民社会” 进行了道德 判定, 其次才在政治意义上理解和应用公民社会。

至近代, 以权利为核心的公民社会虽已不同于古希腊 的文明政治共同体，但从契约的角度分析，公民社会依然 蕴涵着道德品性。一是社会契约订立的自愿性, 彰显着选 择的自由, 反应了公民与国家间富有理性的道德关系; 二 是实现利益的互利性, 体现着尊重个人利益的同时, 明确 了个人对他人和社会的责任, 个人首先是经济主体进而成 为人格的主体; 三是保障权利的公平和正义也是契约的前 提, 权利、公平和正义本身就是一种价值指向, 表达了公 民社会对公民地位平等的追求, 和对专治的否定。由此可 见, 古希腊公民概念中的权利和义务的共生关系在此发生 了偏离, 争取个体权利和利益的重要性被放大了, 但是发 展到一定程度, 公民社会必须寻求权利和义务、共利益和 
个体利益间的合理张力结构。

\section{2 公民社会的当下道德引领}

迄今为止, 按照社会结构的不同, 公民社会已经经历 了和正在经历着: 文明形态、政治形态和文化形态。文明 形态是相对于野蛮时代而言的, 此时的公民社会和政治社 会合二为一, 即亚里士多德把人定义为 “政治性动物” 的 深层次原因。这样的公民社会实质上是少数特权公民自治 的伦理政治共同体。之后, 资产阶级革命完成了公民社会 与国家的分离, 从而确立了公民社会的政治形态, 目的在 于把产生国家的权利从上帝手中移交到普通公民手中, 为 更多的人争取更多的自由和权利。公民为了保护自己的私 利, 在彼此信任的基础上做出的伦理底线意义上的规约, 体现了人们政治法律观念的现代性, 但社会的文明不能仅 仅停留于此, 必然需要道德的引领和提升。加之, 公民社 会并非乌托邦, 自身存在不可避免的内在困境, 如过分强 调对国家的对抗性意义, 就很容易引发社会动荡。有学者 在与科尔伯格的道德推理理论比较后发现, 高水平的道德 推理并没有导致更多的道德行动, 恰恰是建立在共同的宗 教、公民意识和民主观念基础上的共同体身份认同, 更容 易促使公民参与道德行为[3]。文化形态的公民社会更是一 个 “通过人” 并最终 “为了人” 的活动领域, 尤其突显了 它的道德价值, 把自由、平等和权利等以人为目的的道德 价值放在最核心的关注位置, 在根本上符合人类普遍的道 德理性诉求。鉴于此, 公民社会是一个政治范畴、社会范 畴, 甚至法律范畴, 但更是一种道德范畴。对道德品性的 强调更有助于维护社会公正, 更符合公众的普遍利益需求, 同时也更有利于为社会发展获得更多的道德正当性辩护和 支持。

\section{2. 中国公民道德建设的探索}

当权利、自由、平等这些字眼向我们袭来时, 对于经 历了千年臣民社会浸染的古老中国而言, 更是极具诱惑力。 公民道德作为一种理论和实践, 虽然和古希腊罗马的传统 公民社会有着内在关联, 但本质上却是现代性的产物。目 前中国在追求现代化的发展, 公民道德建设是否也要沿着 西方公民道德现代性的道路走下去? 为什么权利本位的自 由公民道德成为近现代西方公民道德的基石后, 又受到诟 病? 这些问题都是我们当前的公民道德建设必须思考的问 题。

\section{1 西方自由主义公民道德的悖论}

“公民”一词起源于古希腊, 它是具有政治权利的自 由民独享统治身份的象征, 区别于奴隶, 公民概念从开始
就奠定了为公民谋取自由和权利的基调。特别是洛克、卢 梭等人在十七世纪阐发的天赋人权论在促使公民成为一种 普通人资格后, 西方自由主义公民道德更是直接为 “占有 性个人主义” 价值观所主导, 强调个人至上性和权利优先 性。“自由主义公民身份有一个恒久不变的共同特点, 即强 调个人权利和自由的持有最大化, 而忽视公民美德和责任, 忽视公共生活, 因而通常被称为 “消极的公民身份” 或 “私 性的公民身份”。” ${ }^{[4]}$ 由此孕育了西方典型的自由主义公民 道德即 “私人权利道德”, 整个社会的制度设计也由道德本 位转向权利本位。客观地讲, 公民的 “私人权利道德” 好 处是不可轻视的, 它几乎赋予了所有人应享有的基本权利, 对于人类来说是一巨大的进步, 这冊庸置疑。但同样冊庸 置疑的是, 公民权利道德从一开始便内含诸多的冲突, 主 要集中体现在个人权利和共同善的冲突中。

当个人权利优先于共同善时, 当公民在行动上用规则 原则取代了美德原则时, 讨价还价的市场机制便伺机超越 市场进入社会关系领域, 建立在原子式个人基础上、服务 于私人利益的公民道德必然成为一种类似于市场的道德。 人们认为只考虑财富才是最聪明的于是对公益事业、公共 事务漠不关心被认为是节制、美德, 从而得到人们的赞许。 此时, 公民轻视公共生活的参与, 缺乏公共精神, 忽视公 民之间的道德联系，公民之间的关系仅仅成为建立在各方 自我利益上的协议关系，是性质上的契约性。“私人权利道 德”一方面导致个体公民道德责任感的缺失, 另一方面因 对个人价值的纵容也导致了社会公认道德准绳的形同虚 设, 其代价是社会的精神和道德危机。

正是针对现代西方公民的道德危机，人们才开回归悠 久的共和主义、社群主义公民道德传统, 才会有麦金泰尔 发出的回归古希腊德性传统的呼喊。由此可见, 西方自由 主义的公民道德并非无可挑剔, 一是其内部本身存在着不 可避免的张力, 二是如果将其移植于我国当下的公民道德 建设, 可能的结果是淮橘为枳。

\section{2 中国传统社会的臣民道德}

公民道德观念的提出本身是种文化产物, 西方特有的 民主文化孕育了特有的公民道德。古代中国, 历史上既未 出现过古希腊城邦意义上的共和政体, 也没有出现过强大 的教权与皇权 (王权) 相抗衡, 自然也就无法孕育出公民 理念。与此不同的是, 专制皇权渗透到社会物质生活和精 神生活的每一个角落, 专制皇权文化孕育出的传统道德实 质是臣民道德。在我国, 更为人们熟知的是 “子民” “臣民” 等带有浓厚奴性色彩的称谓。大致而言, 建立在专制皇权 社会中的臣民道德具有下两大核心特征:

第一，臣民道德提倡义务至上，反对民治和民享。公 
民社会实质是为保护个体利益而出现的, 对国家权力进行 抗衡和制约的自组织力量。但在中国的皇权专制下, 虽然 我们可以找到 “民为贵, 社稷次之, 君为轻 (《孟子・尽心 下》)”, “国以民为本, 社稷亦为民而立” (朱喜《孟子集注》) 此类的表述, 但找不到关于个人自由、权利、参与、平等 之类的表述。孟子的 “民贵” 说也与近代的民权论有本质 的差别, 民权倡导民享、民有、民治, 而孟子中却没有体 现民有、民治的原则, 政治的权利更是不能与民分享的。

甚至到清初黄宗羲的 “民贵” 思想, 其核心仍更多地倾向 于强调中央与地方的分权, 借助地方力量制衡中央君主的 权利, 而非强调民众参与权利的运作, 民众的利益表达和 参与意识显然是不被提倡的。

第二, 臣民道德倡导亲密性私德, 缺失公共道德。近 代以来的西方公民道德建立和运行的基础是公民权利让渡 后达成的社会契约, 中国臣民道德的运行依赖于中国式的 社会契约。所谓中国式社会契约, 建立在费孝通所言的 “差 序格局” 上, 以个人为起点层层外推至家庭、近邻、社区 和国家, 外推的不是西方平等的公民权利而是等级性的伦 理义务; 外推的道德共识也不是适用于陌生人的普遍主义, 而是适合于乡土中国的特殊主义。这种差序格局中的个人 权利是由亲密圈给予, 甚至是赐予的, 而不能由个人主动 争取。如果要挑战权威、争取权利, 那么亲密圈就会取消 这种保护, 甚至会采取严厉的惩罚措施。因此, “亲疏有别” 导致对熟人和陌生人采取双重标准的做法, 极大地伤害了 公共道德的权威性。

\section{3 中国公民道德的初步探索}

在中国, 公民道德思想是在十九世纪末开始输入的, 清末民初也是臣民向公民过渡的尝试时期, “有没有公民可 以把中国历史分为两个时代, 一是臣民社会; 一是公民社 会。什么是臣民社会? 就是权力至上的社会, 在权力社会 中, 权力可以随意剥夺人的生命、财产、尊严等等; 什么 是公民社会? 就是公民权利至上的社会, 一个公民不惧怕 任何人。”[5]此时, 言论出版自由、党派社团蓬勃发展、政 治参与热情高涨都成为我国早期公民道德建设喜微初露的 表征和探索。但是在初步探索的过程中, 中国公民道德建 设也面临着困境和尴尬。

\subsection{1 双重认同和难以兼容的国民道德尝试}

近代中国, 人们习惯于使用 “国民”一词来指称依法 保有国籍的国家成员, 而非 “公民”, 这一点也表明了公民 思想移植的浓重日本烙印。在我国早期国民（公民）道德 探索中, 没有呈现出古希腊公共利益和私人利益的高度一 致, 恰恰相反, 在告别臣民的尝试中, 充满了公民道德与
私民（臣民）道德的双重认同和难以兼容。

以 “国民” 和 “国民道德” 为例, 诸多研究认为 “国 民” 概念是梁启超从日本引进的, 他在引进时是从个人角 度来理解 “国民” (公民) 内涵的, 强调拥有身体保障、自 由、选举权、私有财产等个体权利的不可侵犯性。但作为 深受传统文化影响的士绅阶层, 他的国民道德观又呈现出 西方宪政文化冲击下的二元性特征。一方面, 受卢梭政治 理论的影响梁启超强调主权在民的国家观念, 并在此基础 上提出与 “臣民” 相对的 “国民” 概念。“国民者, 以国为 人民公产之称也”。另一方面, “国民” 概念中的 “群” 意 识却又显露无疑, 反对各私其私的个人本位和功利主义思 想。

显然, 梁启超这里的新公民道德理想不同于以个人权 利为主导的西方近代公民道德, 更接近于崇尚公共善的古 希腊公民美德追求, 是一种国群本位的道德理想, 目的在 于唤醒国民新道德, 塑造新的民族国家。也就是说, 国民 （公民）道德的生存空间仍然直于挽救国家民族危亡的框 架内, 公民道德的尝试依然没有摆脱道德工具化的本质特 征。梁启超前期公民道德思想中呈现的双重认同和难以兼 容, 是那个时代的缩影, 也展现了中国在从臣民社会向公 民社会迈进过程中的艰难选择, 以及选择中的困惑和纠结。 中国公民社会的道德追求从开始就注定了对其的中国式理 解, 也注定了中国的公民道德与西方公民道德的国别性差 异。

\subsection{2 无形臣民道德和有形阶级道德并存的实践}

1949 年的共同纲领和 1954 年的中华人民共和国宪法 明确规定了公民的基本权利和义务, 标志着新中国公民身 份的确立。法律、政治意义上摆脱了臣民身份的人们, 虽 然享有了公民的身份, 但思想和行动仍无法摆脱无形的臣 民枷锁。体现在道德教育领域中, 即新中国虽然摧毁了臣 民道德依存的有形传统政治经济体制, 但无法实现深层次 道德文化的彻底转型。建立在血缘和地缘基础上的臣民道 德暂时隐退了, 无形的权威意识和等级意识并没有随之解 体。传统道德的理想从个体的角度而言是圣贤君子, 从整 体而言就是天下大同, 阶级道德追求的共产主义依然体现 了天下大同的思想。对于道德属性而言, 都是义务的道德, 而非权利的道德。

阶级道德与西方公民道德在哲学基础、道德属性等方 面却表现出截然不同的个性特征。我国阶级道德的哲学基 础是马克思主义的阶级论, 西方公民道德的哲学基础是自 由主义的人权论。“阶级理论是建立在对整个社会历史的经 济利益分析和社会结构关系基础上的科学理论, 而人权理 论则是在反对中世纪封建专制、独裁, 倡导个性自由的思 想解放中创建的价值理论。两者理论的出发点不同, 前者 
是全社会的阶级的, 后者是个体的个人的; 理论的归宿或 目的也不同, 前者是谋求阶级的解放和全人类的自由, 后 者是谋求个人的解放和个体的自由。” [6]因此, 就道德属性 而言, 阶级道德强调的是它的阶级属性因而具有全民性; 西方公民道德强调的是全体公民的人权属性因而具有个体 性。可见, 阶级道德与现代西方公民道德是在两种完全不 同的社会背景下形成的两大道德文化, 构建中国的现代公 民道德不可能完全照搬西方的模式。

\section{3. 中国公民道德教育的研究预设}

一般而言, 世界各国大多在特定历史时期里都会有一 种强势的道德文化主导社会。然而, 经历了改革开放 40 年 的当代中国, 其道德文化的一大特点是, 没有一种能主导 各个领域。1949 年以前是儒家臣民道德主宰的历史; 1949 年到 1978 年期间, 臣民道德在历经多次政治运动的冲击后 日渐式微, 代之而起的是阶级道德, 它借助政权的力量主 导中国三十年; 但是在 1979 年至今的 40 余年间, 随着市 场经济的转型、国家治理方式的转变、民族主义的复兴、 全球化的浪潮, 尤其是西方公民文化的引入, 新的社会关 系结构的形成, 导致中国道德文化中新旧东西要素并存、 相互制衡、相互影响。这样的道德文化既有新的特色, 也 有旧要素的深刻影响。

如何正确总结中国道德传统和当代公民道德建设的经 验, 参考和借鉴现代西方公民道德的内在合理性, 在德性 和契约、个人利益和公共利益等之间寻找合理的张力结构, 创建适合中国社会成长所需的公民道德教育的内生化模 式, 取决于我们对公民道德建设研究的预设。研究预设不 同, 采取的道德教育方式和内容自然有所不同。基于对中 国臣民道德、阶级道德的再度审视, 以及对西方公民道德 的孕育环境和内在悖论的分析, 立足于当前我国公民道德 建设的社会发展背景, 公民道德教育研究应注意预设以下 问题:

一是摆脱关于公民道德教育研究学科化、规范化的视 野, 区分作为观念的公民道德和作为规范的公民道德。不 管是采用 “国家/社会” 二分法, 还是 “国家/社会/市场” 三分法, 立基于观念的视角, 都不能将国家、社会、市场 和公民道德分解、对立开来。经济学、政治学和社会学不 仅仅被理解为科学, 同时还是道德的语言, 即政治、经济 和社会都可以被看作公民道德语言在不同场域的不同诠 释。如果在此意义上界定公民社会, 公民社会应是一个具 有公共精神统领的公民组成的自组织社会, 公民道德不仅 存在于公民社会中, 也会延伸和弥散到公民个体所在的各 个不同领域, 同时, 它也会对不同集体间的关系、集体与 国家的关系以及国家与国家间的关系进行规约。
二是采用一种适合于中国公民社会成长的视角，区分 作为文化传统的公民道德与作为文化移植的公民道德, 建 构有中国性格的公民道德教育体系。一谈到建设公民道德 教育体系, 人们往往会对既有的西方教育传统有种亲近性 认同, 这种认同只是一种初级的事实性认同。由于从臣民 到公民的转变引发的是一个全方位的变迁过程, “我们已经 无法通过简单的事实比较和价值选择来解决复杂的认同问 题, 因为既有的文化事实无论是中国的古老历史还是西方 的现实模式, 都不可能简单地拿来作为我们文化认同的对 象。” [7]因此，公民道德教育体系应是一种建构性认同，即 不是静态的对历史或现实的公民道德教育资源进行价值认 定, 而是以一种积极、参与、建构的方式, 通过对 “什么 是好的” “什么是我们的” 公民道德教育进行开放性讨论, 在动态的过程中持续建构具有中国性格的公民道德教育体 系。

公民道德是一个充满张力的理论范畴, 它不但贯穿西 方社会的文明历程, 涉及西方的自由主义、共和主义等文 化传统, 同时对于当代中国公民道德教育体系的建构具有 重要的启发和借鉴作用, 是中国当代公民道德教育理论形 成的重要理论和实践根源。中国道德文化资源缺乏理性精 神、自由主义和公共道德, 西方公民道德发展恰好呈现出 这些特质, 正是中国道德教育反思自身的理论依据。因此, 探究西方公民道德演进过程中的共性和普适性的成分, 以 及不同成分之间的关系，尤其发现公民道德发展的共同基 础和共同规律，找出激励和抑制中国公民道德发展的具体 原因, 以此寻求适合中国公民道德教育的理论和实践路径。

\section{参考文献(References)}

[1] CAI Xiao-ping. The moral design of Chinese democracy. Gansu Social Sciences, vol. 1, 2007, pp. 233-235.

[2] HOU Yi-fu, China's civil society's development. Party School of the Central Committee of CPC, Doctoral Dissertation, 2009, pp. 35.

[3] James Youniss. When morality meets politics in development. Journal of Moral Education, vol. 38, June 2009, pp. 129-144.

[4] ZHANG Chang-lin. Republication Citizenship and Political Development in Contemporary China .Jinan: Shandong University Press, 2010. pp. 209.

[5] CHEN Yong-sen. Bid farewell to the subjects. Beijing: China Renmin University Press, 2004. pp. 3.

[6] The newsroom of the Journal of Literature, History and Philosophy. Nation and Society. Beijing: The Commercial Press, 2010. pp. 257.

[7] XU Ji-lin. Enlightenment and Anti-enlightenment of Contemporary China. Beijing: Social Sciences Academic Press, 2011. pp. 169. 